\title{
NECK POSTURE MEASUREMENT AMONGST SCHOOLCHILDREN
}

\author{
Gábor Ormos ${ }^{1}$, Rita Kiss ${ }^{2}$ \\ ${ }^{1}$ National Institute for Rheumatology and Physiotherapy, Budapest \\ ${ }^{2}$ Budapest University of Technology and Economics, Department of Structures, \\ Research Center for Biomechanics \\ ormosdr@gmail.com
}

\begin{abstract}
Background: There is a paucity in basic data concerning neck posture in childhood. Our aim was to gain preliminary data on the head/neck/shoulder posture, and to document their evolution with growth in schoolchildren.

Methods: For measuring posture digital photographs were taken of the children seated in a straight-high-backed chair. The camera (Agfa 5Ti, 5.2 megapixels) was located perpendicularly to each subject's height, positioned from the left side, the focus was on the tragus with a standard distance of $150 \mathrm{~cm}$. The first photo was taken in the "neutral head posture" and a second photo in "resting" posture). The digital photos were then evaluated by a computer software program (distributed as Marker Angels). The angles analyzed were as follows: the craniovertebral angle (CVA), the head tilt angle (HTA), the shoulder angle (SHA). Subjects were hundred and fortyseven 9-year old, and hundred and fourtythree 16-year old schoolchildren, who were attending public school in different districts of Budapest.
\end{abstract}

Results: In the 16-year old's group the CVA values have been found reduced significantly (by an average of 8 degrees in neutral position and 6 degrees in resting position) compared to the 9 year olds. The HTA elevated by an average of 1.6 degrees (NS) in neutral position and reduced significantly (by 4.2 degrees) in resting position. The values of the SHA elevated significantly (by an average of 13.33 degrees in neutral position and 13.32 degrees in resting) between the 9-16 year olds, which referred to more protracted shoulder posture.

Discussion: The CVA characterizes the neck posture, the less it's value, the more the forward position. The neck posture is in strong correlation to the head and the shoulder positions. That means forward bent neck position is in correlation to the so called "rounded" shoulder or the shoulder protraction. Although the position of the was found not consequent in neutral position, however was in correlation in resting position.

Conclusion: Measuring head/neck/shoulder posture by means of digital photos and evaulated by computer program proved easy, useful method. We obtained preliminary descriptive data on neck posture in degrees of two age groups of schoolchildren. The comparison of the results proved the tendency of progression in "poor posture" during 7 schoolyears, between in the age of $9-16$.

Keywords: neck posture; schoolchildren's posture; method for measurement 


\section{Introduction}

Our investigation on neck posture has been indicated by the observation that in everyday life more and more schoolchildren look like they have their head held forward and neck postural abnormalities have been found in association with chronic neck pain in adults $2,8,16$. There is a paucity in the literature concerning neck posture measurement in children, we have found studies on schoolchildren's posture in standing $3,6,9,12$, but only one in sitting ${ }^{14}$. To evaluate the "physiological posture“, the term "natural head position” was suggested in cephalometry, measured by x-ray pictures ${ }^{4,5,13}$, Fiebert ${ }^{7}$ determinated "neutral head posture", which differed from the "resting head posture”, definied by Hunten ${ }^{10}$. In most studies posture has been measured by the distance from the vertical line, Braun and Amundson established measuring angles by means of photos, first the craniovertebral angle $(\mathrm{CVA})^{1}$, than Braun measured the shoulder position by the shoulder angle (SHA) ${ }^{2}$. Szeto evaluated the head posture by videorecording, and defined it by the head tilt angle (HTA) ${ }^{16}$. Measuring posture by means of making photos on surface was doupted by Johnson ${ }^{11}$, but later has been validated by two studies ${ }^{14,15}$, and digital camera was used in the largest investigation with children ${ }^{12}$.

Our aim was to gain preliminary data on the head/neck/shoulder posture amongst schoolchildren, the study was designated to determine their neck posture in sitting by measuring the angles mentioned and comparing the two group's data to evaluate the change in the children's posture by aging.

\section{Methods}

Subjects were hundred and fortyseven 9-year old, hundred and thirtyeigth 12 year old and hundred and fourtythree 16-year old school- children who attended a public school, from different districts of the City Budapest. Informed consent was obtained from each child as well as their parents, and approval was also obtained from the institution's ethics committee.

Digital photos were taken seated in a straighthigh-backed chair, with the children touching their scapulae to the back of the chair, thus the effect of the thoracic spine could be excluded. The following anatomical landmarks were identified by small colored adhesive markers: the tragus of the ear, C7 spinous process, and the base of the nose. The subject's position was at right angles, with left side facing the camera (Agfa 5Ti, 5.2 megapixels), the focus was on the tragus with a standard distance of $150 \mathrm{~cm}$ (Figure 1). The first photo was taken in the "neutral head position" (Figure 2. a), which meant that the head is centered over the midline of the body when viewed from either the antero-postero or lateral plane, or with a slight $\left(5^{\circ}\right)$ forward lean ${ }^{7}$. The second photo was taken in a relaxed, "resting" posture ${ }^{7,10}$, shown on Figure 2. b. The digital photos were evaluated by a computer software program (distributed as Marker Angels), which enabled the use of standard protocols for digitizing the angles from the photographs. The angles analyzed were as follows: $\mathrm{CVA}=$ between the line con-

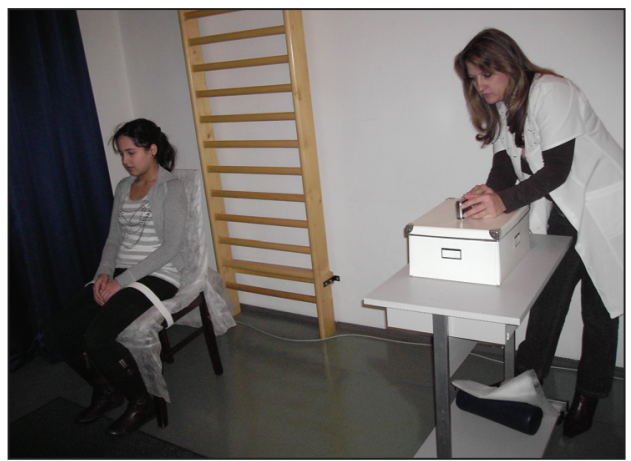

Figure 1. Taking digital photo for measuring neck posture 


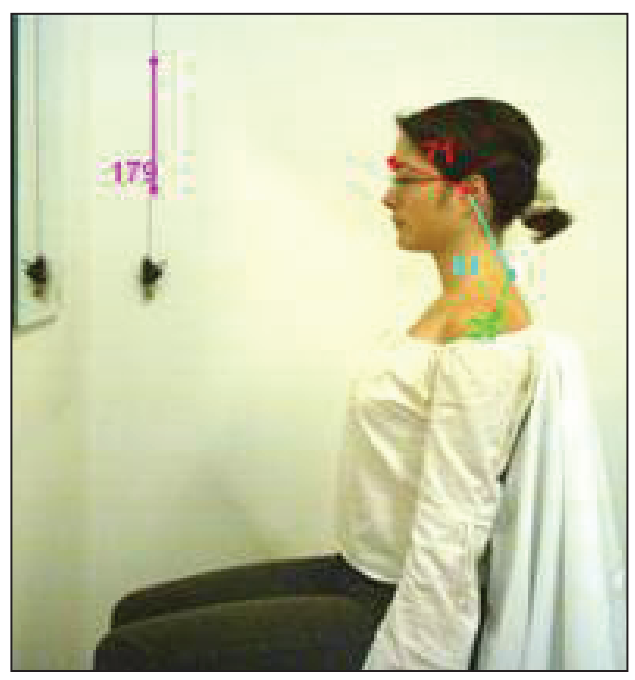

Figure 2. a Neutral head position

necting the tragus and $\mathrm{C} 7$ spinous process and the $\mathrm{x}$-axis, the HTA= between the line connecting the tragus and the base of the nose and the $\mathrm{y}$-axis, shoulder angle $(\mathrm{SHA})=$ between the line connecting the acromion and C7 spinous process and the $\mathrm{x}$-axis (Figure 3 ).

Statistical analysis was made by Student t-test and Spearmen correlation test.

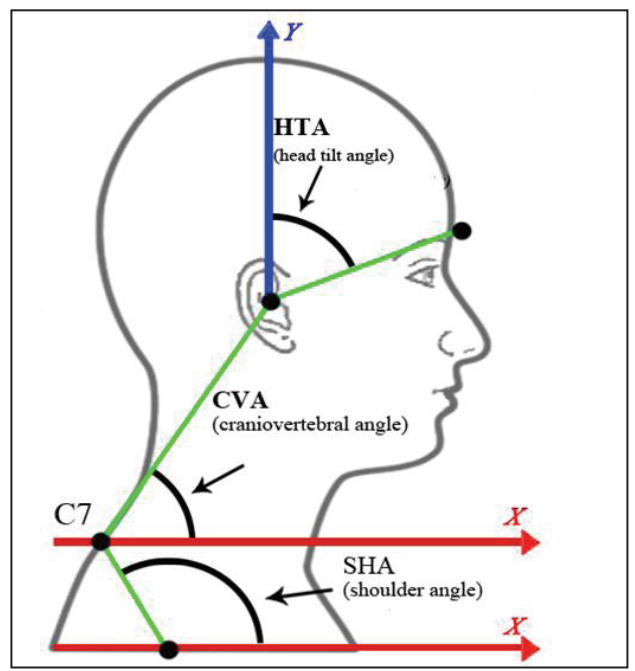

Figure 3. Angles characterising neck posture

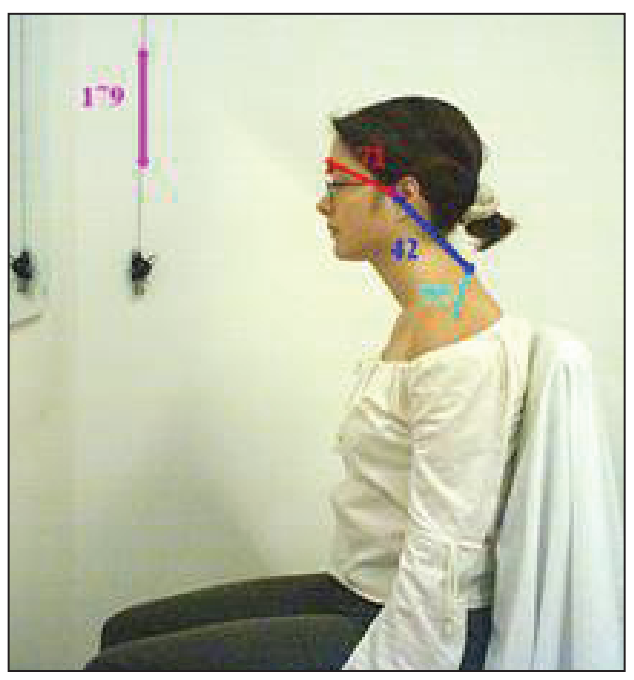

Figure 2. $b$ Resting head position

\section{Results}

The data concerning neck posture angles are shown on Table 1.

The comparison of the data amongst the groups demonstrated that in the 16-year olds CVA values have been found reduced significantly, by an average of 8 degrees $(p=0.0028)$ and 6 degrees $(p=0.0016)$ in resting position compared to the 9 year olds. That meant, neck posture changed into more forward position. The values of the SHA elevated significantly $(\mathrm{p}<0.0001)$, by an average of 13.33 degrees in neutral position and 13.32 degrees in resting between the 9-16 year olds, which referred to more protracted shoulder posture. The HTA was found elevated not significant $(p=0.9145)$ by an average of 1.6 degrees in neutral position and became reduced significantly $(0.0022)$, by 4.2 degrees in resting position. That meant, neck posture changed into forward flexed position, but the head's position was not consequent.

Correlations amongst angles are shown on Table 2. The CVA values measured in neutral 


\begin{tabular}{|c|c|c|c|c|c|}
\hline ANGLES & $\begin{array}{ll}\text { AGE } 9 & n=147 \\
\text { AGE } 16 & n=143\end{array}$ & $\begin{array}{c}\text { MINIMUM } \\
\text { (degree) }\end{array}$ & $\begin{array}{l}\text { MAXIMUM } \\
\text { (degree) }\end{array}$ & $\begin{array}{l}\text { MEAN } \\
\text { (degree) }\end{array}$ & SD \\
\hline \multirow{2}{*}{ CVA neutral } & AGE 9 & 40.00 & 84.00 & 60.30 & 1,88 \\
\hline & AGE 16 & 41.00 & 63.00 & 52.35 & 1.35 \\
\hline \multirow{2}{*}{ CVA, ,resting” } & AGE 9 & 34.00 & 72.00 & 52.98 & 1,87 \\
\hline & AGE 16 & 31.00 & 60.00 & 48.47 & 1.53 \\
\hline \multirow{2}{*}{ HTA neutral } & AGE 9 & 42.00 & 87.00 & 68.26 & 1,27 \\
\hline & AGE 16 & 55.00 & 80.00 & 69.56 & 1.88 \\
\hline \multirow{2}{*}{ HTA ,,resting” } & AGE 9 & 54.00 & 93.00 & 73.74 & 1,72 \\
\hline & AGE 16 & 57.00 & 83.00 & 69.88 & 1.98 \\
\hline \multirow{2}{*}{ SHA neutral } & AGE 9 & 91.00 & 123.00 & 106.41 & 2,74 \\
\hline & AGE 16 & 90.00 & 149.00 & 119.74 & 2.74 \\
\hline \multirow{2}{*}{ SHA ,resting” } & AGE 9 & 91.00 & 124.00 & 107.32 & 2,47 \\
\hline & AGE 16 & 95.00 & 153.00 & 120.64 & 2.54 \\
\hline
\end{tabular}

Table 1. CVA, HTA and SHA values (in degrees)

\begin{tabular}{|c|c|c|c|}
\hline $\mathrm{n}=147+143$ & & & $\begin{array}{c}\text { CVA } \\
\text { neutral }\end{array}$ \\
\hline & \multirow[t]{2}{*}{$\begin{array}{l}\text { HTA } \\
\text { neutral }\end{array}$} & $\begin{array}{l}\text { Correlation } \\
\text { Coefficient }\end{array}$ &,$- 278\left(^{*}\right)$ \\
\hline & & Sig. (2-tailed) & 0,018 \\
\hline & \multirow[t]{2}{*}{$\begin{array}{l}\text { SHA } \\
\text { neutral }\end{array}$} & $\begin{array}{l}\text { Correlation } \\
\text { Coefficient }\end{array}$ &,$- 415\left(^{*}\right)$ \\
\hline & & Sig. (2-tailed) & 0,018 \\
\hline & \multirow[t]{2}{*}{$\begin{array}{l}\text { CVA } \\
\text { resting }\end{array}$} & $\begin{array}{l}\text { Correlation } \\
\text { Coefficient }\end{array}$ &, $722(* *)$ \\
\hline & & Sig. (2-tailed) & 0,000 \\
\hline \multicolumn{4}{|c|}{ ** Correlation is significant at the 0.01 level (2-tailed). } \\
\hline * Correlatio & nific & the 0.05 leve & -tailed). \\
\hline
\end{tabular}

Table 2. Correlations amongst neck angles (by Spearman test)

and resting position were in strong correlation. The CVA neutral values were in negative correlation to HTA and SHA neutral values.

\section{Discussion}

Our results on posture correlate with the relevant literature with children ${ }^{3,6,9,12}$, and also the data published with adults $1,2,16$. The CVA values of age-matched children previously published were slightly lower ${ }^{9}$, but the difference is due to that they were measured in standing. The CVA angle mean value has been found $51,97^{\circ}$ in adults ${ }^{1}$, which roughly equal to our mean data with the 16 year olds. The SHA values measured by us correlated to the data published in adults ${ }^{2}$. The HTA characterizes the head position to the neck, the position of $\mathrm{C} 0 / 1$ joint. The less its degree is, the more extended the head should be. HTA was found (by video recording in adults $57^{\circ 16}$, that was lower than our mean data with children. The HTA neutral mean value of the 16 year olds became slightly higher, but not significantly, compared to the 9 year olds. This is in contradiction to the observations with adults, i.e. the lesser CVA is associated to lesser HTA, which means the head posture changes to an 
extended position. Our different results with children could be explained by the flexibility of the cranio-cervical segment in young age, or that might be due to individual head posture stereotype. In resting position the HTA was in negative correlation to the CVA, as expected. That means with forward bent neck an extended head posture is needed.

The angles measured in neutral and in resting posture were characteristic to what can be seen in real life. The higher degree of SHA referred to the clinical symptom, which should be called "rounded shoulder".

The comparison of the data found in the two age groups (9-16), during 7 years, spent at school, might demonstrate a tendency to "poo- rer posture" with aging. That correlates to the results published by Lafond, who has also found statistically significant associations with age for „forward head translation” and „forward shoulder translation" 12 , which are similar the entities to „forward head/neck position”.

\section{Conclusions}

Measuring head/neck/shoulder posture by means of digital photos and the evaulation by computer program proved easy, useful method. That method should be used for further studies. Descriptive data have been obtained on neck posture in groups of 9 and 16 years old schoolchildren, and we have found a significant tendency to poorer posture with aging.

\section{REFERENCES}

1. Braun BL, Amundson LR. Quantitative assessment of head and shoulder posture. Arch Phys Med Rehabil 1989;70:322-329.

2. Braun BL. Postural differences between asymptomatic men and women and craniofacial pain patients. Arch Phys Med Rehabil 1991;72:653656.

3. Chansirinukor W, Wilson D, Grimmer K, Dansie B. Effects of backpacks on students: measurement of cervical and shoulder posture. Aust. J. Physiother. 2001;47:110-116.

4. Gore DR, Sepic SB, Gardner GM. Roentgenographic findings of the cervical spine in asymptomatic people. Spine 1986;6:521-4.

5. Harrison DD, Janik TJ, Troyanovich SJ, Holland B. Comparisons of lordotic cervical spine curvatures to a theoretical ideal model of the static sagittal cervical spine. Spine 1996;21:667-75.

\section{Cil A, Yazici M, Uzumcugil A, Kandemir $U$,} Alanay A, Alanay Y, Acaroglu RE, Surat A. The evolution of sagittal segmental alignment of the spine during childhood. Spine 2005;30(1): 93-100.

\section{Fiebert I, Roach K, Yang S, Dierking L, Hart F.} Cervical range of motion and strength during resting and neutral head postures in healthy young adults. J. Back Musculosceletal. Rehabilitation 1999;12:165-178.

8. Griegel-Morris P, Larson K, Mueller-Klaus K, Oatis $C A$. Incidence of common postural abnormalities in the cervical, shoulder, and thoracic regions and their association with pain in two age groups of healthy subjects. Phys Ther 1992; (72):425-431.

9. Grimmer KA, Williams MT, Gill TK. The associations between adolescent head-on-neck posture, backpack weight, and anthropometric features. Spine. 1999;24:2262-2267.

10. Hanten WP, Lucio RM, Russell JL, Brunt D. Assessment of total head excursion and resting 
head posture. Arch. Phys. Med. Rehabil. 1991; 72:877-880.

11. Johnson GM. The correlation between surface measurement of head and neck posture and the anatomic position of the upper cervical vertebrae. Spine. 1998;23:921-927.

12. Lafond D, Descarreaux $M$, Normand MC, Harrison $D E$. Postural development in school children: a cross-sectional study. Chiropr Osteopat. 2007 Jan 4;15:1.

13. Lundstrom A, Lundstrom F, Lebret LM, Moorrees CF. Natural head position and natural head orientation: basic considerations in cephalometric analysis and research. Eur. J. Orthod. 1995;17:111-120.
14. van Niekerk SM, Louw Q,Vaughan C, GrimmerSomers K, Schreve K. Photographic measurement of upper-body sitting posture of high school students: a reliability and validity study. BMC Musculoskelet Disord. 2008 Aug 20;9: 113.

15. Refshauge KM, Goodsell M, Lee M. The relationship between surface contour and vertebral body measures of upper spine curvature. Spine. 1994;19:2180-2185.

16. Szeto GP, Straker L, Raine S. A field comparison of neck and shoulder postures in symptomatic and asymptomatic office workers. Appl. Ergon. 2002;33:75-84.

\section{Gábor Ormos}

National Institute for Rheumatology and Physiotherapy, Budapest 